\section{Changes in Sprint, Change of Direction, and Jump Performance during a Competitive Season in Male Lacrosse Players}

\section{Christopher Thomas ${ }^{1}$, David Mather ${ }^{2}$ and Paul Comfort ${ }^{1 *}$}

\begin{abstract}
This study aimed to examine performance changes in lacrosse players during a 24-week competitive season (including 22 weeks of periodized resistance training (RT)). Eleven male lacrosse players (age $24.5 \pm 4.3$ years, height $180.4 \pm 5.6 \mathrm{~cm}$, body mass $80.5 \pm 5.7 \mathrm{~kg}, 1$ repetition maximum (1RM) back squat (BS) $113.3 \pm$ $17.8 \mathrm{~kg}, 1 \mathrm{RM}$ power clean (PC) $67.2 \pm 19.7 \mathrm{~kg}$ ) participated in this study. Testing included 5-, 10-, 20-m sprints, change of direction (COD), countermovement jump (CMJ), and squat jump (SJ). Testing sessions occurred during week one (T-1), week six (T-2), week 15 (T-3), and week 24 (T-4) of a domestic season. Significant improvements in 20-m sprint performance occurred from T-1 to T-4 (3.04 \pm 0.07 seconds, $2.98 \pm 0.08$ seconds, $p=0.018)$. Left leg COD tests significantly improved from T-1 to T-2 $(3.20 \pm 0.15$ seconds, $3.10 \pm 0.13$ seconds, $p=0.005)$, and T-1 to T-4 $(3.20 \pm$ 0.15 seconds, $3.07 \pm 0.12$ seconds, $p=0.014)$. Right leg COD tests significantly improved from T-1 to T-4 $(3.20 \pm 0.15$ seconds, 3.08 \pm 0.12 seconds, $p=0.002)$, and T-3 to T-4 $(3.20 \pm 0.15$ seconds $3.08 \pm 0.12$ seconds, $p=0.001)$. SJ height significantly decrease from T-1 to T-2 (38.2 \pm 2.63 centimeters, $36.7 \pm 2.57$ centimeters, $p=0.008$ ). Results demonstrate that improvements in sprint and COD performance can occur during the season in male lacrosse players engaged in periodized RT, therefore coaches and strength and conditioning coaches should focus on development rather than maintenance in season.
\end{abstract}

\section{Keywords}

Periodization; Sprint performance; Power; Monitoring

\section{Introduction}

Physiological profiling of athletes, particularly longitudinal investigations of physiological characteristics, can provide valuable information to coaches and sports scientists. The physiological requirements of lacrosse are not fully understood due to a limited amount of research, however research suggests physical qualities such as speed, strength, power, agility, and aerobic and anaerobic endurance are highly important [1]. According to several authors, success in sport depends upon the development of strength and power qualities, all of which contribute to sprint, COD, and sports

*Corresponding author: Paul Comfort, Human Performance Laboratory, Directorate of Sport, Exercise and Physiotherapy, University of Salford, Salford Greater Manchester, United Kingdom, Email: p.comfort@salford.ac.uk

Received: May 29, 2014 Accepted: August 30, 2014 Published: September 05, 2014 performance [2,3]. Performance measures such as strength, power, and speed are often monitored and assessed to indicate an athlete's current level of physical performance as well as response to a training stimulus. Video analysis of work: rest intervals in National Collegiate Athletic Association (NCAA) Division I men's lacrosse reported that performance relied primarily on anaerobic metabolism [4], although no direct metabolic measurements were calculated. Research on male club team lacrosse players has indicated that aerobic capacity levels in these athletes are similar to values seen in college basketball, team handball, and ice hockey athletes but less than observed in soccer players [5-7]. Similarly, power output in Lacrosse players has also shown to be much lower than that seen for other anaerobic athletes (i.e. football and basketball players) $[5,6]$. To the author's knowledge, these are the only two studies on male lacrosse players, describing the physiological needs of lacrosse, and detailing performance variables for male club players $[4,6]$.

Several studies have documented the physiological and anthropometric characteristics of professional athletes [8-11] Although these studies have described the physical characteristics of professional athletes and provided insight into the physiological demands of several sports such as soccer [9], lacrosse [7,12], rugby league [8], and basketball [13] all of these studies have been limited to a single measurement performed at the beginning, middle, or end of the competitive season. Because of the competitive demands and the limited time available for fitness development during the playing season, it is possible that athletes could experience residual fatigue, with the fitness of players declining throughout a season [14].

Extensive research has examined the magnitude of change in performance expected over short periods of time in highly trained athletes [15-17] and more recently over extended periods of time [1823]. Appleby et al. [18] found 6.5-11.5\% increases in upper and lower body strength over 2 years in rugby union players, whereas increases in upper body strength of approximately $23 \%$ have been observed over 10 years in elite rugby league players [20]. Changes in performance have been observed during the course of a single competitive season $[22,24]$. Collegiate soccer players observed decreases in sprint speed and vertical jump performance towards the end of the season compared to preseason values [21]. National level softball athletes have shown to increase peak velocity and peak power in the jump squats, as well as increases in absolute and relative lower body strength through pre-, mid- and post-season performance testing whilst partaking in a periodized resistance training programme [22]. Sheppard et al. [23] found changes in jump, and strength performance over two years in volleyball players as they transitioned from junior to senior national playing level. Little scientific evidence, however, exists regarding the magnitude of change in performance measures that can be expected over a long-term period in lacrosse players.

Several investigations have reported the performance changes that occur during the season in female athletes of various sports, including lacrosse, volleyball, field hockey, tennis, basketball, and handball [22,24-28] but despite the attention given to performance assessments by sports scientists, there is a paucity of research examining sprint, $\mathrm{COD}$, and jump performance changes that occur during the season in male lacrosse athletes. Recently, Stodden and Galitski [29] examined 
longitudinal sprint, COD, and jump performance changes in collegiate football players, confirming that greatest performance gains are generally seen during athletes first year of intercollegiate competition. Kraemer et al. [27] demonstrated that during a collegiate soccer season, significant decrements in 20 -yd sprint speed (4\%) and vertical jump (14\%) were observed whilst following an in-season RT program of $75-85 \% 1 \mathrm{RM}$, however concurrent aerobic endurance training was based on individual preference, which could have influenced the findings. It was reported elsewhere that collegiate soccer players maintained 9.1-m and 36.5-m sprint, and vertical jump performance throughout a competitive season in whilst following an unplanned nonlinear periodization format [30]. Performance changes during a competitive season have been observed in state rugby league players [14], where improvements in COD (2\%), and stable improvements in 10-, 20-, and 40-m sprint performance were identified during the early stages of the season, with reductions in muscular power and maximal aerobic power towards the end of the season, when training loads were lowest and injury rates highest.

Although maximizing the long-term development of strength is one of the primary goals of strength and conditioning programs, much of what we know about the neurological and morphological adaptations to RT arise from short-term (i.e., commonly 8- to 12week interventions). This is a serious limitation of current knowledge because the principle of diminished returns dictates that initial improvements in muscular function are easily invoked and further improvements are progressively harder to achieve [31]. Therefore, the purpose of this study was to examine performance changes that occur in male lacrosse players during a 24-week competitive season (including 22 weeks of periodized RT). It was hypothesized that this information will assist strength and conditioning professionals in designing optimal training programs and assisting lacrosse athletes with developing sport-specific training goals.

\section{Methods}

\section{Experimental approach to the problem}

To assess the performance changes that occur throughout the season of concurrently training lacrosse players, assessments of sprint, COD, CMJ height, and SJ height were conducted on a group of national level lacrosse players on four occasions over a 24 week period. We tested 3 measurements consisting of sprint performance (5-, 10-, and 20-m sprint), COD left and right leg (standardized COD drill), and jump height (CMJ and SJ height), as these have been observed to be key athletic abilities within lacrosse [12]. Initial testing commenced after a 3-week general preparation phase that included familiarization with all lifts and drills associated with testing to increase reliability of baseline measures. Testing sessions occurred during week one (T1), week six (T2), week 15 (T3) and week 24 (T4); therefore T1 was initial testing, T2 followed a hypertrophy mesocycle, T3 occurred following strength 1 and power 1 periods, and T4 represented final testing, after the strength 2 and power 2 periods. All testing sessions were supervised by a certified strength and conditioning specialist.

\section{Subjects}

Eleven national lacrosse players (2 Goalies, 3 Defenders, 4 Midfielders, 2 Attackers; age $24.5 \pm 4.3$ years, height $=180.4 \pm 5.6$ $\mathrm{cm}$, body mass $=80.5 \pm 5.7 \mathrm{~kg}, 1 \mathrm{RM} \mathrm{BS}=113.3 \pm 17.8 \mathrm{~kg}, 1 \mathrm{RM}$ $\mathrm{PC}=67.2 \pm 19.7 \mathrm{~kg}$ ) participated in this investigation. Participants had $\geq 6$ months (range 6-12 months) of structured resistance training experience. All athletes volunteered for the testing as part of their normal training and monitoring regime. Ethical approval was provided by the Institutional Review Board, and all athletes provided written informed consent. All procedures conformed to the Declaration of Helsinki. Twenty eight players began the current investigation, but this reduced to $n=11$ completing all four testing sessions due to injury or illness.

\section{Procedures}

Tests were selected to assess sprint, COD, and jump performance in male lacrosse players. Athletes attended the human performance laboratory on four occasions, at the same time of day, for each testing day. Performance measures of sprints (5, 10, and 20-m), COD, CMJ height, and SJ height were assessed on the same day, during the active rest week, during week one (T-1), week six (T-2), week 15 (T-3), and week 24 (T-4). The active recovery week involved a continuation with all training except RT. The order of tests were as follows; sprint performance (5-, 10-, and 20-m sprint), COD left leg, COD right leg, CMJ height, and SJ height. Tests were interspersed with 8-minute rest periods in accordance with McBride et al. [32] and this was standardized across each testing session. Athletes had abstained from training for 48 hours prior to testing and were asked to maintain a consistent fluid and dietary intake on each day of testing. Before the start of each test day, athletes were instructed to perform a standardized dynamic warm-up, as directed by their certified strength and conditioning specialist.

\section{Training}

Athletes continued with their normal training program for a typical season, although the athletes in this study were from the England national squad, they are not professional and therefore train and compete part-time. This involved conditioning and speed sessions in addition to RT sessions while engaging in normal skills training for 2-4 sessions ( $\geq 6$ hours) per week (Table 1 ).

The RT program was designed to maximize the long-term development of strength and power. Therefore the T-1 testing was classified as a "preseason", followed by an "in season" period from T-2 to T-3, with T-4 testing occurring upon completion of the domestic competitive season. The athletes performed all the same lower body lifts twice a week, and the same speed and anaerobic conditioning sessions (Tables 1-6). Moreover, this study focused on lower body

Table 1: Average duration and number of resistance training, conditioning, and skills sessions, including the number of matches per week during each phase of the year.

\begin{tabular}{|l|c|c|c|c|}
\hline \multicolumn{1}{|c|}{ Phase of the year } & $\begin{array}{c}\text { Average } \\
\text { duration (wks) }\end{array}$ & Resistance sessions & Conditioning sessions & Skills sessions \\
\hline Preseason & $8-10$ & $3-4$ & $3-4$ & $3-4$ \\
\hline Domestic competition & $22-24$ & $2-3$ & $1-2$ & 0 \\
\hline Recovery & 2 & 0 & 0 & 0 \\
\hline International season & $4-6$ & $1-2$ & $1-2$ & $1-2$ \\
\hline Off-season & $8-10$ & 2 & $1-2$ & $1-2$ \\
\hline
\end{tabular}


Table 2: Example of training program during hypertrophy mesocycle.

\begin{tabular}{|c|c|c|c|c|c|}
\hline \multirow{2}{*}{$60-70 \% 1 \mathrm{RM}$} & \multicolumn{2}{|c|}{ Session 1} & \multirow{2}{*}{$60-70 \% 1 \mathrm{RM}$} & \multicolumn{2}{|c|}{ Session 2} \\
\hline & Sets & Reps & & Sets & Reps \\
\hline \multicolumn{3}{|l|}{ Exercise } & \multicolumn{3}{|l|}{ Exercise } \\
\hline Front Squat & 4 & 8 & Deadlift & 4 & 8 \\
\hline Romanian Deadlift (RDL) & 4 & 8 & Jump Squat & 4 & 8 \\
\hline Mid-Thigh Clean Pull & 4 & 8 & Nordic Curls & 4 & 3 \\
\hline Military Press & 3 & 8 & Push Press & 3 & 8 \\
\hline Pull Ups (Wide grip) & 3 & 8 & Pull Ups (Close grip) & 3 & 8 \\
\hline Press Ups & 3 & 8 & Dips & 3 & 8 \\
\hline
\end{tabular}

Table 3: Example of training program during STR-1 mesocycle.

\begin{tabular}{|c|c|c|c|c|c|}
\hline \multirow{2}{*}{$80-85 \%$ 1RM } & \multicolumn{2}{|c|}{ Session 1} & \multirow{2}{*}{$80-85 \%$ 1RM } & \multicolumn{2}{|c|}{ Session 2} \\
\hline & Sets & Reps & & Sets & Reps \\
\hline \multicolumn{3}{|l|}{ Exercise } & \multicolumn{3}{|l|}{ Exercise } \\
\hline Front Squat & 3 & 4 & Deadlift & 3 & 4 \\
\hline Midthigh Clean Pull & 3 & 4 & Jump Squat & 3 & 4 \\
\hline Push Press & 3 & 4 & Push Press & 3 & 4 \\
\hline RDL & 3 & 4 & Nordic Curls & 3 & $4-6$ \\
\hline Pull Ups (Wide grip) & 3 & 8 & Pull Ups (Close grip) & 3 & 8 \\
\hline Press Ups & 3 & 8 & Dips & 3 & 8 \\
\hline
\end{tabular}

Table 4: Example of training program during PWR-1 mesocycle.

\begin{tabular}{|c|c|c|c|c|c|}
\hline \multirow{2}{*}{$60-80 \%$ 1RM } & \multicolumn{2}{|c|}{ Session 1} & \multirow{2}{*}{$60-80 \%$ 1RM } & \multicolumn{2}{|c|}{ Session 2} \\
\hline & Sets & Reps & & Sets & Reps \\
\hline \multicolumn{3}{|c|}{ Exercise } & \multicolumn{3}{|c|}{ Exercise } \\
\hline Front Squat & 3 & 5 & Deadlift & 3 & 4 \\
\hline Box Jump & 3 & 6 & Power Clean & 3 & 4 \\
\hline RDL & 3 & 3 & Jump Squat & 3 & 6 \\
\hline Hang Clean Pull & 3 & 3 & Push Press & 3 & 6 \\
\hline Push Press & 3 & 3 & Nordic Curls & 3 & $4-6$ \\
\hline
\end{tabular}

adaptations throughout the season as this was controlled more among all the players of the squad (Tables 2-6). Some modifications to exercises were made during the program (power clean to midthigh clean pull) if required due to technique or injury status. During the preseason phase, RT sessions were typically characterized as hypertrophy (60-75\% 1RM, 20-25 sets (12-15 lower body, 6 upper body) of 8-12 reps per session). The in season phase was characterized by lower volume (15-20 sets (10 lower body, 6 upper body) of 4-6 reps per session) strength, and power sessions (60-85\% 1RM). Ranges of $60-85 \% 1 \mathrm{RM}$ were chosen based on previous research identifying the 'optimal load' for peak force and peak power output on specific exercises [33-38]. Mesocycles were systematically sequenced in integrative 4-week blocks with a lighter (lower volume) week being the last week of each cycle, in order to optimize specific training outcomes at pre-determined time points [39]. Percentage based intensity 1RM loads were based on prior 1RM test scores established previously. A maintenance of intensity with a lower volume of strength exercises occurred in the power mesocycle with the addition of jump squats, complex training, and variations of the power clean in line with current research for optimizing power output [40-42]. Athletes were monitored at all RT sessions by an accredited strength and conditioning coach. During the preseason and in season phases, technical and tactical skill sessions were the predominant form of conditioning, incorporating a high conditioning running component Additional conditioning sessions were prescribed on an individual player basis in accordance to their needs analysis. Skill sessions involved components of individual player skill development training (i.e., position specific small team technique and tactics), full team
Table 5: Example of training program during STR-2 mesocycle.

\begin{tabular}{|c|c|c|c|c|c|}
\hline \multirow{2}{*}{$80-90 \%$ 1RM } & \multicolumn{2}{|c|}{ Session 1} & \multirow{2}{*}{$60-85 \% 1 R M$} & \multicolumn{2}{|c|}{ Session 2} \\
\hline & Sets & Reps & & Sets & Reps \\
\hline \multicolumn{3}{|c|}{ Exercise } & \multicolumn{3}{|c|}{ Exercise } \\
\hline Back Squat & 3 & $4-6$ & Front Squat & 3 & $4-6$ \\
\hline Midthigh Clean Pull & 4 & $4-6$ & Hang Power Clean & 4 & $4-6$ \\
\hline RDL & 3 & $4-6$ & Nordic Curls & 3 & $4-6$ \\
\hline Jump Squat & 3 & $4-6^{*}$ & Split Jerk & 3 & 4 \\
\hline
\end{tabular}

Table 6: Example of training program during PWR-2 mesocycle.

\begin{tabular}{|c|c|c|c|c|c|}
\hline & \multicolumn{2}{|c|}{ Session 1} & \multirow{2}{*}{$60-70 \% 1 R M$} & \multicolumn{2}{|c|}{ Session 2} \\
\hline & Sets & Reps & & Sets & Reps \\
\hline \multicolumn{3}{|c|}{ Exercise } & \multicolumn{3}{|c|}{ Exercise } \\
\hline Jump Squat & 3 & $4-6^{*}$ & Hang Power Clean & 4 & $4-6$ \\
\hline Hang Clean Pull & 3 & $4-6^{\#}$ & Split Jerk ${ }^{*}$ & 4 & $4-6$ \\
\hline Back Squat & 3 & $3^{*}$ & Push Press & 3 & $4-6$ \\
\hline Nordic Curls & 3 & $4-6^{*}$ & Nordic Curls* & 3 & $4-6$ \\
\hline${ }^{*}$ Body mass & \multicolumn{2}{|c|}{${ }^{\# 70 \%} 1-\mathrm{RM}$} & $\%$ 1-RM & & \\
\hline
\end{tabular}

training, and simulated match play. The number of sessions per week ranged from two to four and was of varying lengths (90-150 minutes).

\section{Sprint testing}

After a standardized warm-up, athletes performed three $20-\mathrm{m}$ sprints on an indoor track (Mondo, SportsFlex, $10 \mathrm{~mm}$; Mondo America Inc., Mondo, Summit, NJ, USA), wearing standard training shoes. Sprints were interspersed with a 1-minute rest period in accordance with McBride et al. [32]. Time to 5, 10, and 20-m was assessed using infrared timing gates (Brower, Speed Trap 2, Wireless Timing System, Draper, UT, USA). All athletes began with their front foot positioned $0.5 \mathrm{~m}$ behind the start line and were instructed to perform all sprints with a maximal effort. Previous research has shown test - re-test measurements of sprint performance, change of direction speed, and reactive agility to be reliable. The (intraclass correlation coefficients) ICC and typical error of measurement (TE) for 5-, $10-$, and $20-\mathrm{m}$ sprint were $r=0.84-0.96$, and $1.3 \%$ to $3.2 \%$, respectively [43].

\section{COD testing}

Change of direction was assessed via a standardized COD test performed for both left and right sides on an indoor track (Mondo, SportsFlex $10 \mathrm{~mm}$; Mondo America Inc., Mondo, Summit, NJ, USA), with time to completion measured by timing gates (Newtest Powertimer 1.0 Testing System and Contact Mat; Oulu, Finland) positioned at the start and end of the drill. COD tests for each side were interspersed with a 1-minute rest period. As with the sprint test, COD tests were performed on the indoor track, with all athletes beginning with their front foot $0.5 \mathrm{~m}$ behind the start line and were instructed to perform all sprints with a maximal effort [8]. For the left leg the athlete sprints forwards to a marker on the floor, touching this with their left foot, where they back pedal $2.5 \mathrm{~m}$ at a 135 angle, to another marker, touching this with their right foot, and then sprint forwards a further 5 meters through the timing gates (Figure 1). The mirror image of this is performed for the right leg. Previous research has demonstrated a high level of reliability $(r=0.98, p<0.001)$ between trails for the COD drill for both left and right legs, respectively [8].

\section{Jump testing}

To determine jump height, athletes were asked to perform 


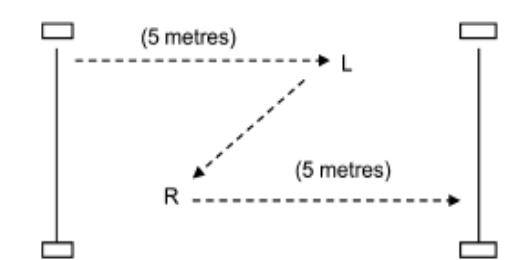

Start

\section{Finish}

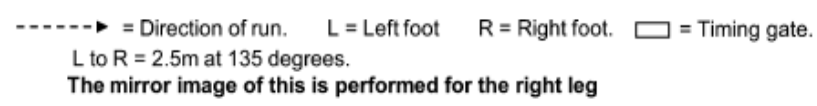

Figure 1: Example of agility test.

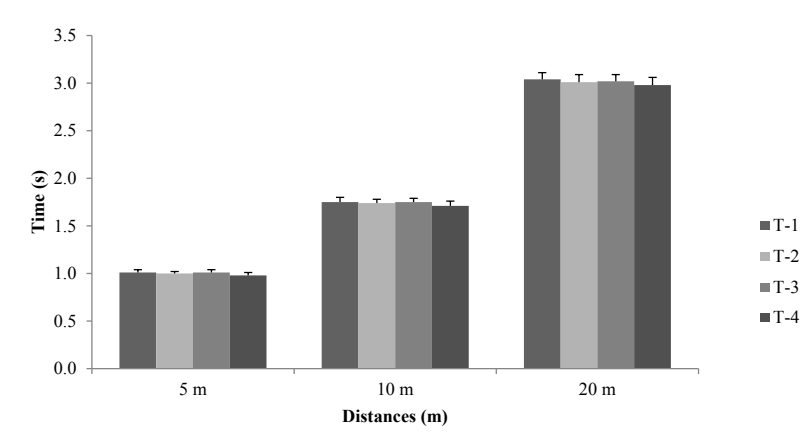

* Significantly $(p<0.018)$ quicker than T-1

Figure 2: Changes in sprint performance during a competitive season.

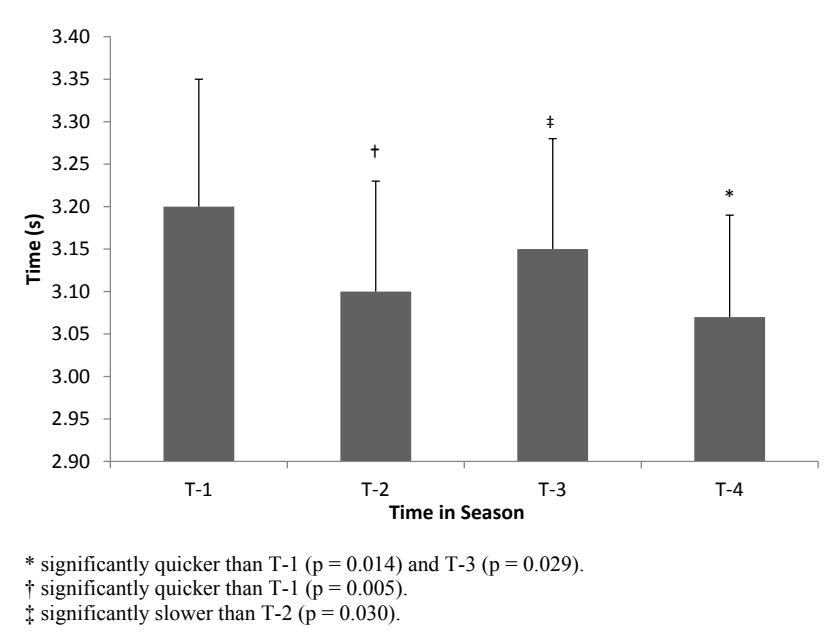

Figure 3: Changes in agility performance performed with the left leg during a competitive season.

bodyweight CMJ and SJ without the aid of an arm swing; this was standardized by having athletes perform the jumps with hands on hips. The CMJ involved flexion of the knee followed immediately by extension of the legs. The SJ involved athletes to squat to approximately $45^{\circ}$ of knee flexion, pause, and then instructed to jump. Attempts that included an increase in knee flexion before jumping were excluded and athletes asked to repeat that attempt. Athletes performed 3 jumps with a 1-minute rest between each attempt for both conditions. Jump
Table 7: Speed, agility, and jump performance values over the study period during week one (T1), week six (T-2), week 15 (T-3), and week 24 (T-4).

\begin{tabular}{|l|l|l|l|l|}
\hline Variable & T-1 & T-2 & T-3 & T-4 \\
\hline $5 \mathrm{~m}(\mathrm{~s})$ & $1.01 \pm 0.08$ & $1.00 \pm 0.08$ & $1.01 \pm 0.10$ & $0.98 \pm 0.01$ \\
\hline $10 \mathrm{~m}(\mathrm{~s})$ & $1.75 \pm 0.15$ & $1.74 \pm 0.12$ & $1.75 \pm 0.13$ & $1.71 \pm 0.15$ \\
\hline $20 \mathrm{~m}(\mathrm{~s})$ & $3.04 \pm 0.21$ & $3.01 \pm 0.23$ & $3.02 \pm 0.20$ & $2.98 \pm 0.24$ \\
\hline Agility Left (s) & $3.20 \pm 0.46$ & $3.10 \pm 0.41$ & $3.16 \pm 0.40$ & $3.07 \pm 0.38$ \\
\hline Agility Right (s) & $3.21 \pm 0.45$ & $3.15 \pm 0.41$ & $3.20 \pm 0.43$ & $3.08 \pm 0.36$ \\
\hline CMJ (cm) & $40.07 \pm 1.08$ & $39.43 \pm 1.19$ & $39.56 \pm 1.33$ & $40.36 \pm 0.96$ \\
\hline SJ (cm) & $38.24 \pm 0.79$ & $36.72 \pm 0.78$ & $37.66 \pm 1.04$ & $39.02 \pm 1.24$ \\
\hline
\end{tabular}

height was recorded using a jump mat (Newtest Powertimer 1.0 Testing System and Contact Mat; Oulu, Finland). This method has previously shown high levels of reliability $(r=0.967-0.97)$ in determining jump height $[44,45]$, when compared to 3-camera motion analysis system. This system determines flight time, which is converted to jump height using the following equation: $1 / 8\left(g . t^{2}\right)$ (where $g=$ the acceleration due to gravity and $t=$ air time). Performance using a timing mat can be influenced by body position during flight; therefore athletes were instructed and carefully observed to maintain straight legs while airborne. If the knees were bent or raised, the trial was discarded and the participant was given another attempt following a 1-minute rest period [32].

\section{Statistical analyses}

Statistical analyses were performed using SPSS version 17.0 (SPSS, Inc., Chicago, IL, USA). To determine the reliability of each assessment ICC between trials of each assessment were conducted, using the criteria of Cortina [46], where $r>0.80$ is excellent. Changes in performance measures over time were analyzed by repeated measures analysis of variance (ANOVA), with significant main effects examined by Bonferroni post hoc analysis. The dependent variables were time in 5, 10, and 20-m sprint (seconds), time in left and right leg COD drill (seconds), CMJ and SJ height (centimeters). A criterion alpha level of $p \leq 0.05$ was used to determine statistical significance. All data are reported as mean $\pm S D$. To examine the magnitude of the changes in the dependent variables, effect size (ES) was also calculated for all measures using the following formula: ES = post-test mean pre-test mean/pre-test $S D$. Effect statistics were discussed as trivial $(<0.35)$, small $(0.35-0.80)$, moderate $(0.80-1.50)$, or large $(>1.5)$ as recommended for recreationally trained subjects [47].

\section{Results}

Intraclass correlations demonstrated a high level of reliability between trials for the 5-, 10-, and 20-m sprints $(\mathrm{r}=0.98, p=0.001 ; \mathrm{r}=$ $0.97, p=0.001 ; \mathrm{r}=0.98, p=0.001$, respectively), COD drill $(\mathrm{r}=0.99, p$ $=0.001$; for both left and right legs), CMJ height $(\mathrm{r}=0.96, p=0.001)$, and SJ height $(\mathrm{r}=0.91, p=0.001)$.

Sprint performance significantly improved with small effect for 20 - $\mathrm{m}$ from T-1 to T-4 (3.04 \pm 0.07 seconds, $2.98 \pm 0.08$ seconds, $p$ $=0.018, \mathrm{ES}=0.79$, power $=0.98)($ Figure 2 and Table 8$)$. Significant improvements in COD performance with the left leg were observed with small to moderate effect from T-1 to T-2 $(3.20 \pm 0.15$ seconds, $3.10 \pm 0.13$ seconds, $p=0.005, \mathrm{ES}=0.67$, power $=0.96), \mathrm{T}-3$ to $\mathrm{T}-4$ ( $3.15 \pm 0.13$ seconds, $3.07 \pm 0.12$ seconds, $p=0.029$, $\mathrm{ES}=0.60$, power $=0.89)$, and $\mathrm{T}-1$ to $\mathrm{T}-4(3.20 \pm 0.15$ seconds, $3.07 \pm 0.12$ seconds, $p$ $=0.014$, ES $=0.82$, power $=0.98$ ) (Figure 3 ). In addition, there was a significant decrease in performance with small effect in COD test performed with left leg from T-2 to T-3 $(3.10 \pm 0.13$ seconds, $3.15 \pm$ 
Citation: Thomas C, Mather D, Comfort P (2014) Changes in Sprint, Change of Direction, and Jump Performance during a Competitive Season in Male Lacrosse Players. $J$ Athl Enhancement 3:5

doi:http://dx.doi.org/10.4172/2324-9080.1000167

Table 8: Percentage change in Speed, agility, and jump performance values during each study period.

\begin{tabular}{|c|c|c|c|c|c|c|c|c|c|c|c|c|}
\hline \multirow{2}{*}{ Variable } & \multicolumn{2}{|l|}{$\mathrm{T} 1-\mathrm{T} 2$} & \multicolumn{2}{|l|}{$\mathrm{T} 1-\mathrm{T} 3$} & \multicolumn{2}{|l|}{$\mathrm{T} 1-\mathrm{T} 4$} & \multicolumn{2}{|l|}{$\mathrm{T} 2-\mathrm{T} 3$} & \multicolumn{2}{|l|}{$\mathrm{T} 2$ - T4 } & \multicolumn{2}{|l|}{ T3 - T4 } \\
\hline & $\%$ Change & Effect Size & $\%$ Change & Effect Size & $\%$ Change & Effect Size & $\%$ Change & Effect Size & $\%$ Change & Effect Size & $\%$ Change & Effect Size \\
\hline $5 \mathrm{~m} \mathrm{(s)}$ & -0.01 & -0.35 & 0.00 & 0.08 & -0.03 & -1.05 & 0.01 & 0.45 & -0.02 & -0.73 & -0.03 & -0.86 \\
\hline $10 \mathrm{~m}(\mathrm{~s})$ & -0.01 & -0.27 & 0.00 & -0.05 & -0.02 & -0.78 & 0.01 & 0.29 & -0.01 & -0.66 & -0.02 & -0.91 \\
\hline $20 \mathrm{~m}(\mathrm{~s})$ & -0.01 & -0.36 & -0.01 & -0.30 & -0.02 & -0.79 & 0.00 & 0.05 & -0.01 & -0.40 & -0.01 & -0.54 \\
\hline Agility Left (s) & -0.03 & -0.67 & -0.01 & -0.29 & -0.04 & -0.82 & 0.02 & 0.42 & -0.01 & -0.17 & -0.03 & -0.60 \\
\hline Agility Right (s) & -0.02 & -0.37 & 0.00 & -0.04 & -0.04 & -0.83 & 0.02 & 0.36 & -0.02 & -0.52 & -0.04 & -0.84 \\
\hline $\mathrm{CMJ}(\mathrm{cm})$ & -0.02 & -0.18 & -0.01 & -0.14 & 0.01 & 0.08 & 0.00 & 0.03 & 0.02 & 0.02 & 0.02 & 0.18 \\
\hline SJ (cm) & -0.04 & -0.58 & -0.02 & -0.33 & 0.02 & 0.29 & 0.02 & 0.26 & 0.06 & 0.89 & 0.04 & 0.47 \\
\hline
\end{tabular}

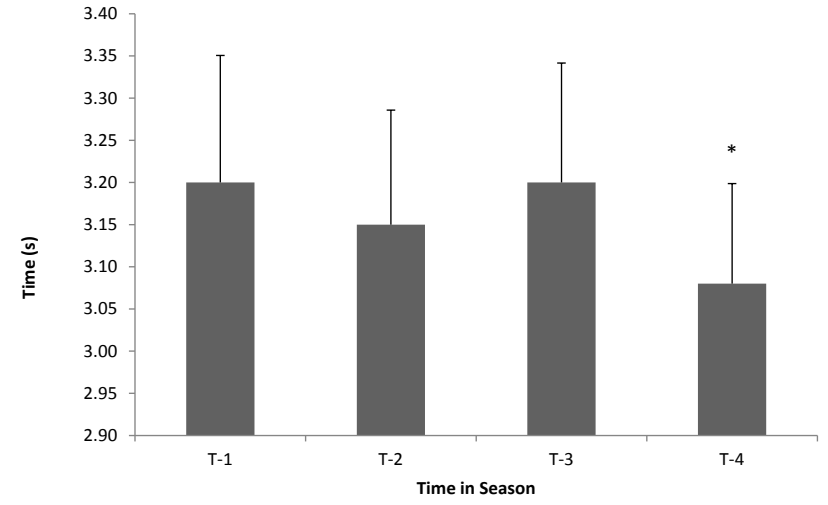

Figure 4: Changes in agility performance performed with the right leg during a competitive season.

0.13 seconds, $p=0.030, \mathrm{ES}=0.42$, power $=0.75)($ Figure 3 and Table $8)$.

COD tests performed with the right leg were significantly improved with moderate effect from T-1 to T-4 (3.20 \pm 0.15 seconds, $3.08 \pm 0.12$ seconds, $p=0.002$, $\mathrm{ES}=0.83$, power $=1.00$ ), and $\mathrm{T}-3$ to T-4 $(3.20 \pm 0.15$ seconds, $3.08 \pm 0.12$ seconds, $p=0.001$, ES $=0.84$ power $=0.95)($ Figure 4 and Table 8$)$. There was a significant decrease and small effect in SJ height from T-1 to T-2 (38.2 \pm 2.63 centimeters, $36.7 \pm 2.57$ centimeters, $p=0.008$, $\mathrm{ES}=0.58$, power $=0.61$ ) (Figure 5 and Table 8).

\section{Discussion}

Sprint performance significantly improved (2\%) for $20-\mathrm{m}$ from T-1 to T-4 (3.04 \pm 0.07 seconds, $2.98 \pm 0.08$ seconds). Sprint times for the lacrosse athletes are faster than the majority of $10-\mathrm{m}$ (range $=$ $1.79-1.85$ seconds) and $20-\mathrm{m}$ (range $=3.09-3.15$ seconds) sprint times available in published literature across a competitive season $(17,18)$ Although these improvements do not indicate changes in competitive performance, they can give the strength and conditioning coach information in response to the desired training intervention, and help guide future training programming. Whether the improvements in sprint performance came as a direct consequence of increased strength or whether both are a function of the periodized RT program incorporated into the athletes' in-season training is unclear as maximal strength changes were not tested in the current study. Based on the fact that peak ground reaction forces and impulse are strong determinants of sprint performance [48-52], it is likely, however, that increased force production via performing a periodized RT program including heavy strength training ( $>85 \% 1 \mathrm{RM})$ may have contributed to improved $20-\mathrm{m}$ sprint performance.

In many sports, body weight must be accelerated quickly during

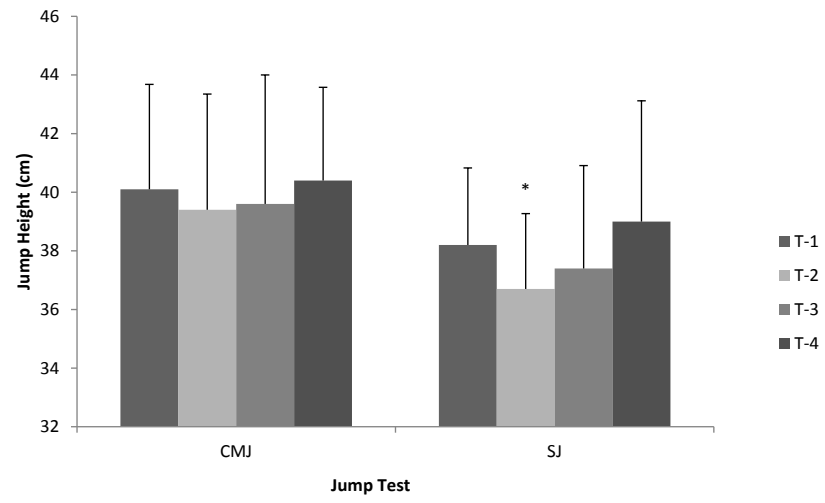

Figure 5: Changes in jump height during a competitive season.

sprints and jumps. To support this assumption, it must be noted that the relationship between maximum strength and power output is shown for both low and high loads [53]. In many sports, low loads, such as kicking and throwing, and high loads, such as body weight during sprints and jumps, must be accelerated [54,55]. Athletes must possess sufficient strength to overcome or accelerate body mass. McBride et al. [32] found a small-to-moderate relationship between absolute strength in the back squat and sprint performance [56]. Relative strength, as well as absolute strength values, has also previously been evaluated in relation to sports performance. Previous data values for football players are between $1.7-1.9 \mathrm{~kg} / \mathrm{kg}$ in the parallel back squat $[33,57]$, in contrast to values reported in the current study $(1.4 \mathrm{~kg} /$ $\mathrm{kg}$ ). Wisloff et al. [57] found relative strength values of $2.2 \mathrm{~kg} / \mathrm{kg}$ for soccer players in the half squat. Generally, deeper squats correspond to a smaller amount of lifted weight, therefore, when comparing the values of the current athletes with those of the soccer players, the achieved values of the soccer should instead be used to demonstrate the high level of training of the soccer players, rather than a reference point for athletes in other sports.

The findings of this study are in line with those of previous research by Stodden and Galatski [29] wherein collegiate football players demonstrated significant improvements in 40-yd sprint performance (1\%), and COD performance (7\%) after the first year of training, however, no details of the athletes RT program were mentioned in the study. Although the current studies also indicated similar improvements of $2 \%$ and $0-4 \%$ in $20-\mathrm{m}$ sprint, and COD performance, respectively, the findings should be interpreted with caution due to the testing protocols carried out (i.e. 20-m vs. 40-yd (36.6-m), standardized COD drill vs. pro-agility).

Young et al. [58] identified linear sprint speed as an important physical factor in agility performance. Because there were no 
significant improvements in 5-, and 10-m sprint performance, changes in sprint ability cannot account for the improvements in COD performance in the current study. However, the significant improvements for the COD test performed on the left leg on more testing occasions than the right leg ( $3 v s .2)$, may be a result of this side being the "weaker" or non-dominant side and therefore having more potential for improvement. In addition, there was a significant decrease in COD performance (2\%) with the left leg from T-2 to T-3 (Figure 3) potentially due to the lack of eccentric hamstring and quadriceps strength, and the ability to decelerate, due to preceding RT mesocycles appearing dominated by movements that target the quadriceps, with a limited volume of eccentric training for the hamstrings. It is recommended that lacrosse athletes amend current training practices to increase the focus on eccentric hamstring and quadriceps strength, and the ability to decelerate (jump landings and COD drills). This is particularly relevant considering the frequent sprint and change of direction during play, requiring to accept greater breaking forces when decelerating and changing direction [4].

Because no body fat and body mass measures were performed, it is not possible, from the results of this investigation, to determine whether performance changes in sprint, COD, and jump height over a competitive season were influenced by an increase in lean mass, with a reduction in total skin fold thickness. In sports where relative strength is of importance, training should be aimed at increasing strength and power, while maintaining very low fat mass to reduce stress placed on the musculoskeletal system [23]. The combination of greater body mass, and reduced skin fold thickness, could lead to similar or faster sprint times, leading to greater momentum, which is likely to result in an increase in impact force during collisions, in turn increasing the difficulty for an opponent to stop or tackle the player. The implications for this would be the requirement for players to condition themselves to accept higher impact forces and offset a possible increase in the risk of collision injury.

Vertical jump performance has shown to significantly increase (4\%) after a year of training in college football players [29], whereas no improvements were identified in the current study in either CMJ or SJ (4\% decrease). The CMJ height observed in the current study $(39-40 \mathrm{~cm})$ is dramatically lower $(>6 \mathrm{~cm})$ that previously found in soccer and rugby league players across a competitive season (45-63 $\mathrm{cm})[14,24,30,59]$. It is worth noting, however, that these studies did allow subjects to use their arms during the countermovement. This, and differences in measurement methods used, may account for some of the difference in height jumped.

The lack of improvements in sprint and jump performance in the current study may have been due to the insufficient total volume or stimulus of the strength and/or power training performed during the in-season. A meta-analytic review of strength training protocols [60] concluded that athlete populations can improve strength by performing a strength training session of 8 sets per muscle group 2 times per week, with a mean training intensity of $85 \% 1 \mathrm{RM}$. This supports findings from the current study that, although athletes did perform 2 sessions per week, the RT program prevented the athletes from achieving the possible training volume required to increase lower-body strength. Due to 1RM strength not being assessed regularly across the season, it is unknown whether the lack of improvement in sprint and jump performance was due to lack of strength improvement or muscular and neural factors. Theoretically an increase in relative strength would be expected to result in improvements in sprint and jump performance as these both rely heavily on the acceleration of body mass and the ability to overcome inertia. Other possible explanations for lack of improvements could be muscular factors such as muscle fibre type and muscle hypertrophy, or neural factors such as the ability to utilise the stretch-shortening cycle (SSC), motor unit recruitment, and rate coding. Although preseason testing was followed by a hypertrophy mesocycle (weeks 2-5), it is unlikely to produce significant increases in cross sectional area (CSA) which has shown to correlate to greater force production $(\mathrm{r}=0.70)$ [61]. Due to the current athlete's limited previous RT experience, athletes may not have had high Type II muscle fibres which appear to have strong relationships to strength and power generating ability [62,63]. Larger motor units are activated in response to higher external loads, and synchronization of motor units involves the simultaneous activation of numerous motor units, leading to high rates of force development and force output [64]. It could be hypothesized that RT programming could have been designed in a more sequential manner in order to increase CSA and strength to a greater extent before commencing power type training. Research has shown among weaker athletes, strength training produced as good or better increases in rate of force development and power than did power training $[65,66]$. Subjects with a low relative strength level $(1.28-1.32 \mathrm{~kg} / \mathrm{kg})$ who performed back squats at $75-90 \%$ for 10 weeks showed significant increases compared to a power training group (jump squats with $0-30 \% 1 \mathrm{RM}$ ) in strength (31.2 vs. $4.5 \%)$, peak power (17.7 vs. 17.6\%) and sprint performance ( $2.2 v s .3 .6 \%)$, respectively, indicating that adaptations were specific to the training stimulus. In another study, Cormie et al. [66] found stronger subjects $(1.97 \mathrm{~kg} / \mathrm{kg})$ to elicit increases in maximal power $(18 \%$; ES $=1.60)$ and jump height $(7 \mathrm{~cm})$ in 5 weeks that took weaker athletes $(1.32 \mathrm{~kg} / \mathrm{kg})$ to achieve similar improvements in 10 weeks, showing stronger athletes adapt to power training faster and with greater magnitude. This method has previously proved effective showing improvements in parallel squat, vertical jump, and sprint performance in Division I college football players, however the study showed no notation of other training factors such as sprint, agility, or plyometric training [67].

The strength of this research includes the ecological validity and longitudinal investigation of performance results that allows for examination of \% change through preseason and in-season for national-level male lacrosse athletes. However, between certain testing sessions, COD and jump performance changes displayed levels of statistical power $(<0.8)$, questioning the small participant size as a possible limitation, and therefore these findings should be interpreted with caution. The sample size in this study was small $(n=11)$, and it is unknown whether tests would reach statistical significance with larger numbers due to increased statistical power. The inherent nature of following a team over a competitive season can limit subject numbers (i.e. team selection, training camps, competition schedule, positional demands, and injuries), and this should be taken into consideration when interpreting the findings of the study. Additionally, due to the aforementioned logistical issues, 1RM testing was not possible to test during the in-season. It would have been advantageous since 1RM scores may have changed (positively or negatively) and this possibly diminished the accuracy of the actual percentage based 1RM loads that were applied during the periodized RT programme. The findings of this current research is limited to male lacrosse players with similar experience, but results of the current study suggest for further investigations into the performance changes of male lacrosse players to a competitive season.

A limitation of this research is that there was no control group, 
Citation: Thomas C, Mather D, Comfort P (2014) Changes in Sprint, Change of Direction, and Jump Performance during a Competitive Season in Male Lacrosse Players. J Athl Enhancement 3:5

therefore it is not possible to determine how much of the changes in performance are attributable to the RT and 'normal' skill based training that the participants were also performing. The aim of the investigation however, was not to determine the effects of RT on performance across a season, but to monitor changes in sprint, COD and jump performance across a season.

\section{Practical Applications}

This study provides insight into sprint, COD, and jump performance changes that occur over the course of a season in male lacrosse athletes that has not previously been documented. Furthermore, it demonstrates the ability for an in-season plan to increase measures of performance variables. The periodized program, involving strength and power emphasized mesocycles, used in this study demonstrates that RT has large benefits of not only maintaining but also improving sprint, and COD performance during preseason and in-season training. Therefore, the inclusion of a RT program throughout the in-season training should be considered by coaches and strength and conditioning specialist to be of high importance. Although this study provides evidence as to the potential for performance changes in male lacrosse athletes, a much larger body of research with increased subjects is needed to investigate the issues surrounding adaptation and improvement of male lacrosse performance. Particularly, the relationships between strength and power improvements and transfer to sprint, COD, and jump performance in male athletes are topics that need a large amount of attention in future research.

\section{Acknowledgements}

The authors would like to thank the participants for their involvement in the study. The authors have no conflict of interest in presenting this data, and no funding was received to support this study.

\section{References}

1. Walker JR (1980) How to Play Winning Lacrosse. Cornerstone Library.

2. Jones $P$, Bampouras TM, Marrin K (2009) An investigation into the physical determinants of change of direction speed. J Sports Med Phys Fitness 49: 97-104.

3. Sheppard JM, Young WB (2006) Agility literature review: classifications, training and testing. J Sports Sci 24: 919-932.

4. Plisk SS (1994) Regression analyses of NCAA division I final four men's lacrosse competition. The J Strength Cond Res 8: 28-42.

5. Hoffman J (2006) Norms for Fitness, Performance, and Health. Human Kinetics.

6. Steinhagen MR, Meyers MC, Erickson HH, Noble L, Richardson MT (1998) Physiological Profile of College Club-Sport Lacrosse Athletes. J Strength Cond Res 12: 226-231

7. Vescovi JD, Brown TD, Murray TM (2007) Descriptive characteristics of NCAA Division I women lacrosse players. J Sci Med Sport 10: 334-340.

8. Comfort P, Graham-Smith P, Matthews MJ, Bamber C (2011) Strength and power characteristics in English elite rugby league players. J Strength Cond Res 25: 1374-1384.

9. Comfort P, Stewart A, Bloom L, Clarkson B (2014) Relationships between strength, sprint, and jump performance in well-trained youth soccer players. J Strength Cond Res 28: 173-177.

10. Gabbett TJ, Kelly JN, Sheppard JM (2008) Speed, change of direction speed and reactive agility of rugby league players. J Strength Cond Res 22: 174 181.

11. Wisløff U, Helgerud J, Hoff J (1998) Strength and endurance of elite soccer players. Med Sci Sports Exerc 30: 462-467.

12. Vescovi JD, McGuigan MR (2008) Relationships between sprinting, agility, and jump ability in female athletes. J Sports Sci 26: 97-107.
13. Hoffman JR, Tenenbaum G, Maresh CM, Kraemer WJ (1996) Relationship between Athletic Performance Tests and Playing Time in Elite College Basketball Players. J Strength Cond Res 10: 67-71.

14. Gabbett TJ (2005) Changes in physiological and anthropometric characteristics of rugby league players during a competitive season. J Strength Cond Res 19: 400-408.

15. Chelly MS, Fathloun M, Cherif N, Ben Amar M, Tabka Z, et al. (2009) Effects of a back squat training program on leg power, jump, and sprint performances in junior soccer players. J Strength Cond Res 23: 2241-2249.

16. Comfort P, Haigh A, Matthews MJ (2012) Are changes in maximal squat strength during preseason training reflected in changes in sprint performance in rugby league players? J Strength Cond Res 26: 772-776.

17. Newton RU, Kraemer WJ, Häkkinen K (1999) Effects of ballistic training on preseason preparation of elite volleyball players. Med Sci Sports Exerc 31: 323-330.

18. Appleby B, Newton RU, Cormie P (2012) Changes in strength over a 2-year period in professional rugby union players. J Strength Cond Res 26: 25382546.

19. Baker DG, Newton RU (2008) Observation of 4-year adaptations in lower body maximal strength and power output in professional rugby league players. J Aust Strength Cond 16: 3-10.

20. Baker DG (2013) 10-year changes in upper body strength and power in elite professional rugby league players--the effect of training age, stage, and content. J Strength Cond Res 27: 285-292.

21. Kraemer WJ, French DN, Paxton NJ, Häkkinen K, Volek JS, et al. (2004) Changes in exercise performance and hormonal concentrations over a big ten soccer season in starters and nonstarters. J Strength Cond Res 18: 121 128

22. Nimphius S, McGuigan MR, Newton RU (2012) Changes in muscle architecture and performance during a competitive season in female softball players. J Strength Cond Res 26: 2655-2666.

23. Sheppard JM, Nolan E, Newton RU (2012) Changes in strength and power qualities over two years in volleyball players transitioning from junior to senior national team. J Strength Cond Res 26: 152-157.

24. Häkkinen K (1993) Changes in physical fitness profile in female basketbal players during the competitive season including explosive type strength training. J Sports Med Phys Fitness 33: 19-26.

25. Häkkinen K (1993) Changes in physical fitness profile in female volleyball players during the competitive season. J Sports Med Phys Fitness 33: 223-232.

26. Hoffman JR, Ratamess NA, Neese KL, Ross RE, Kang J (2009) Physical performance characteristics in national collegiate athletic association division iii champion female lacrosse athletes. J Strength Cond Res 23: 1524-1529.

27. Kraemer WJ, Hakkinen K, Triplett-Mcbride NT, Fry AC, Koziris LP, et al (2003) Physiological changes with periodized resistance training in women tennis players. Med Sci Sports Exerc 35: 157-168.

28. Marques MC, Tillaar Rv, Vescovi JD, González-Badillo JJ (2008) Changes in strength and power performance in elite senior female professional volleyball players during the in-season: a case study. J Strength Cond Res 22: 1147-1155.

29. Stodden DF, Galitski HM (2010) Longitudinal effects of a collegiate strength and conditioning program in American football. J Strength Cond Res 24 2300-2308.

30. Silvestre R, Kraemer WJ, West C, Judelson DA, Spiering BA, et al. (2006) Body composition and physical performance during a National Collegiate Athletic Association Division I men's soccer season. J Strength Cond Res 20: $962-970$.

31. Wilson G, Murphy AJ, and Walshe AD (1997) Performance benefits from weight and plyometric training: Effects of initial strength level. Coach Sport Sci J 2: 3-8.

32. McBride JM, Blow D, Kirby TJ, Haines TL, Dayne AM, et al. (2009) Relationship between maximal squat strength and five, ten, and forty yard sprint times. J Strength Cond Res 23: 1633-1636.

33. Comfort P, Allen M, and Graham-Smith P (2011) Comparisons of peak ground reaction force and rate of force development during variations of the power clean. J Strength Cond Res 25: 1235-1239. 
Citation: Thomas C, Mather D, Comfort P (2014) Changes in Sprint, Change of Direction, and Jump Performance during a Competitive Season in Male Lacrosse Players. J Athl Enhancement 3:5

34. Cormie P, McCaulley GO, Triplett NT, McBride JM (2007) Optimal loading for maximal power output during lower-body resistance exercises. Med Sc Sports Exerc 39: 340-349.

35. Kawamori N, Rossi SJ, Justice BD, Haff EE, Pistilli EE (2006) Peak force and rate of force development during isometric and dynamic mid-thigh clean pulls performed at various intensities. J Strength Cond Res 20: 483-491.

36. Kilduff LP, Bevan H, Owen N, Kingsley MI, Bunce P, et al. (2007) Optima loading for peak power output during the hang power clean in professional rugby players. Int J Sports Physiol Perform 2: 260-269.

37. Stone MH, O'Bryant HS, McCoy L, Coglianese R, Lehmkuhl MB, et al. (2003) Power and maximum strength relationships during performance of dynamic and static weighted jumps. J Strength Cond Res 17: 140-147.

38. Suchomel TJ, Wright GA, Kernozek TW, Kline DE (2014) Kinetic comparison of the power development between power clean variations. J Strength Cond Res 28: 350-360.

39. Plisk SS, Stone MH (2003) Periodization Strategies. Strength Cond J 25 19-37.

40. Cormie P, McGuigan MR, Newton RU (2011) Developing maxima neuromuscular power: part 2 - training considerations for improving maximal power production. Sports Med 41: 125-146.

41. Kawamori N, Crum AJ, Blumert PA, Kulik JR, Childers JT, et al. (2005) Influence of different relative intensities on power output during the hang power clean: identification of the optimal load. J Strength Cond Res 19: 698708

42. McBride JM, Nimphius S, Erickson TM (2005) The acute effects of heavyload squats and loaded countermovement jumps on sprint performance. J Strength Cond Res 19: 893-897.

43. Leard JS, Cirillo MA, Katsnelson E, Kimiatek DA, Miller TW, et al. (2007) Validity of two alternative systems for measuring vertical jump height. $J$ Strength Cond Res 21: 1296-1299.

44. Markovic G, Dizdar D, Jukic I, Cardinale M (2004) Reliability and factorial validity of squat and countermovement jump tests. J Strength Cond Res 18 551-555.

45. Cortina JM (1993) What is coefficient alpha? An examination of theory and applications. J Appl Psychol 78: 98-98.

46. Rhea MR (2004) Determining the magnitude of treatment effects in strength training research through the use of the effect size. J Strength Cond Res 18 : 918-920.

47. Hunter JP, Marshall RN, McNair PJ (2005) Relationships between ground reaction force impulse and kinematics of sprint-running acceleration. J Appl Biomech 21: 31-43.

48. Kawamori N, Nosaka K, Newton RU (2013) Relationships between ground reaction impulse and sprint acceleration performance in team sport athletes. J Strength Cond Res 27: 568-573.

49. Weyand PG, Lin JE, Bundle MW (2006) Sprint performance-duration relationships are set by the fractional duration of external force application. Am J Physiol Regul Integr Comp Physiol 290: R758-765.

50. Weyand PG, Sternlight DB, Bellizzi MJ, Wright S (2000) Faster top running speeds are achieved with greater ground forces not more rapid leg movements. J Appl Physiol (1985) 89: 1991-1999.

51. Wright S, Weyand PG (2001) The application of ground force explains the energetic cost of running backward and forward. J Exp Biol 204: 1805-1815.

52. Reilly T (2006) The Science of Training - Soccer: A Scientific Approach to Developing Strength, Speed and Endurance. Taylor \& Francis.

53. Verheijen R (1998) The Complete Handbook of Conditioning for Soccer. Reedswain Videos and Books.

54. Moss BM, Refsnes PE, Abildgaard A, Nicolaysen K, Jensen J (1997) Effects of maximal effort strength training with different loads on dynamic strength, cross-sectional area, load-power and load-velocity relationships. Eur J Appl Physiol Occup Physiol 75: 193-199.

55. Harris NK, Cronin JB, Hopkins WG, Hansen KT (2008) Relationship between sprint times and the strength/power outputs of a machine squat jump. J Strength Cond Res 22: 691-698.
56. Baker DG, Newton RU (2008) Comparison of lower body strength, power, acceleration, speed, agility, and sprint momentum to describe and compare playing rank among professional rugby league players. J Strength Cond Res 22: $153-158$.

57. Wisløff U, Castagna C, Helgerud J, Jones R, Hoff J (2004) Strong correlation of maximal squat strength with sprint performance and vertical jump height in elite soccer players. Br J Sports Med 38: 285-288.

58. Young WB, James R, Montgomery I (2002) Is muscle power related to running speed with changes of direction? J Sports Med Phys Fitness 42: 282-288.

59. Gabbett TJ (2005) Physiological and anthropometric characteristics of junior rugby league players over a competitive season. J Strength Cond Res 19 : 764-771.

60. Peterson MD, Rhea MR, Alvar BA (2005) Applications of the dose-response for muscular strength development: a review of meta-analytic efficacy and reliability for designing training prescription. J Strength Cond Res 19: 950958.

61. Häkkinen K, Keskinen KL (1989) Muscle cross-sectional area and voluntary force production characteristics in elite strength- and endurance-trained athletes and sprinters. Eur J Appl Physiol Occup Physiol 59: 215-220.

62. Bottinelli R, Canepari M, Pellegrino MA, Reggiani C (1996) Force-velocity properties of human skeletal muscle fibres: myosin heavy chain isoform and temperature dependence. J Physiol 495: 573-586.

63. Fry AC, Schilling BK, Staron RS, Hagerman FC, Hikida RS, et al. (2003) Muscle fiber characteristics and performance correlates of male Olympicstyle weightlifters. J Strength Cond Res 17: 746-754.

64. Semmler JG (2002) Motor unit synchronization and neuromuscular performance. Exerc Sport Sci Rev 30: 8-14.

65. Cormie P, McGuigan MR, Newton RU (2010) Adaptations in athletic performance after ballistic power versus strength training. Med Sci Sports Exerc 42: 1582-1598.

66. Cormie P, McGuigan MR, Newton RU (2010) Influence of strength on magnitude and mechanisms of adaptation to power training. Med Sci Sports Exerc 42: 1566-1581

67. Harris GR, Stone MH, O'bryant HS, Proulx CM, Johnson RL (2000) Shortterm performance effects of high power, high force, or combined weighttraining methods. J Strength Cond Res 14: 14-20.

\section{Author Affiliation}

${ }^{1}$ Human Performance Laboratory, Directorate of Sport, Exercise and Physiotherapy, University of Salford, Salford, Greater Manchester, United Kingdom

${ }^{2}$ High Performance Conditioning, University of Salford, Salford, Greater Manchester, United Kingdom

Submit your next manuscript and get advantages of SciTechnol submissions
* 50 Journals
* 21 Day rapid review process
* 1000 Editorial tean
* 2 Million readers
* Publication immediately after acceptance
* Quality and quick editorial, review processing

Submit your next manuscript at • www.scitechnol.com/submission 